upon a well coordinated and skilled team of medical and paramedical staff. These facilities are difficult enough to draw together in a district general hospital, let alone a small, general practitioner based unit. Despite the possibility that rheumatology may not be a core specialty in the new health service it is unlikely that the discipline will find it possible, or desirable, to sever its links with hospital medicine.

An intermediate approach might be to increase the sessional commitment to clinics based in the community. Such use of peripatetic care has been evaluated and found useful in other chronic disease specialties, such as diabetology. ${ }^{10}$ Community based consultant sessions might be used to support 'specialist' general practitioners, who would be able to liaise closely with the rheumatology department, as well as to provide local outpatient clinics. Balanced against the advantages, however, are the potential loss of time spent travelling and administering such a system and the effects of removing consultant cover from the hospital base. Perhaps telephone or even video links might help to avoid these problems.

Another dimension of rheumatological practice which has begun to receive attention is the educational role of the hospital based rheumatologist. Examination of general practitioner referrals to rheumatologists in Leicester ${ }^{11}$ showed wide variation in the referral rates of individual practitioners. Such data suggest that auditing of referral practices might enable identification of groups of general practitioners who would benefit from rheumatological education. A study of referral practices within Bristol, however, suggested that the vast majority of general practitioners referred patients appropriately (Stellakis $e t a l$, unpublished data). On this basis, an educational strategy targetted at the whole population of general practitioners seems more prudent. Clearly, referral patterns within small areas are prone to considerable geographical variation. ${ }^{12}$ Determination of appropriate educational strategies will inevitably entail research into these local circumstances.

\section{Incorporating strategies in the NHS}

In conclusion, rheumatic disorders constitute a major financial and health burden for the British population. The present provision for these disorders seems to fall short of the demand for them. We urgently need to measure this shortfall and consider alternative methods for the delivery of rheumatological care, both within the hospital system and the community.

The changes proposed in the government white paper ${ }^{13}$ will always impose a financial drive towards community based care for chronic illnesses and disability. ${ }^{14}$ It is imperative that rheumatologists consider the available options in a constructive and wholehearted manner. We shall have to measure the clinical benefit or loss which patients accrue in relation to proposed or actual changes in the provision or organisation of rheumatological care, and to advocate those which are shown to be therapeutically preferrable. If we do not, working practices which are not palatable may well be forced upon us from without.

Rheumatology Unit,

University Department of Medicine,

Bristol Royal Infirmary,

Bristol BS2 8HW

1 Wood P H N, ed. The challenge of arthritis and rheumatism. A report on problems and progress in health care for rheumatic disorders. London: British League against Rheumatism, 1977.

2 District Rheumatology Services. A report on the committee on rheumatology of the Royal College of Physicians of London. Br $\mathcal{F}$ Rheumatol 1988; 27: $54-61$.

3 Wood P H N. The changing spectrum of disability: the increasing burden of arthritis. Rehabilitation 1973; 84: 5-11.

4 Linos A, Worthington J W, O'Fallon W M, Kurland L T. The epidemiology of rheumatoid arthritis in Rochester, Minnesota: a study of incidence, prevalence and mortality. Am $\mathcal{F}$ Epidemiol 1980; 111: 87-98.

5 Lawrence R C, Hochberg M C, Kelsey J L, et al. Estimates of the prevalence of selected arthritis and musculoskeletal disease in the United States. f Rheumatol 1989; 16: 427-41.

6 Felson D T, Naimark A, Anderson J, Kazis L, Castelli W, Meenan R F. The prevalence of knee osteoarthritis in the elderly. The Framingham osteoprevalence of knee osteoarthritis in the elderly.
arthritis study. Arthritis Rheum 1987; 30: 914-8.

7 Dugowson C E, Bley L, Koepsell T D, Nelson J L, Daling J R. Incidence of Dugowson C E, Bley L, Koepsell T D, Nelson J L, Daling J R. Incidence of
rheumatoid arthritis in women [Abstract]. Arthritis Rheum 1989; 32: S63. rheumatoid arthritis in women [Abstract]. Arthritis Rheum 1989; 32: S63.
Bamji A, Dieppe P A, Hasloch I, Shipley M. What do rheumatologists do? A pilot audit study [Abstract]. Br f Rheumatol 1987; 26 (suppl 1): 56-7.

9 Doherty $M$. 'Chondroprotection' by non-steroidal anti-inflammatory drugs. Ann Rheum Dis 1989; 48: 619-21.

10 Home P, Walford S. Diabetes care. Whose responsibility? Br Med J 1984; 289: $713-4$.

11 Samanta A, Roy S. Referrals from general practice to a rheumatology clinic. Br Y Rheumatol 1988; 27: 74-6.

12 Wilkin D, Smith A. Explaining variation in general practitioner referrals to hospital. Family Practice 1987; 4:160-9.

13 Secretaries of State for Health, Wales, Northern Ireland and Scotland. Working for Patients. London: HMSO, 1989 (Cmnd 555).

14 Haslock I. Working for patients? Br f Rheumatol 1989; 28: 185-6.

\title{
International conferences: Are they any use?
}

The gluttons for punishment who enjoy international conferences will be delighted to learn that of 327 members of the British Society for Rheumatology who replied to a questionnaire about them, $89 \%$ wished to see their continuation, though only $53 \%$ went regularly to such conferences. Few would doubt the value of small groups from different disciplines meeting to discuss a narrowly defined subject. The scientific content of the bigger gatherings was not rated highly (only 16\%), though only $15 \%$ thought they were completely useless. Educational aspects fared a little better, in that $90 \%$ thought there was value in these, but again only $17 \%$ rated this feature highly. The American Rheumatism Association meetings were held up as a model of excellence for their educational update. Perceived value of international conferences was in the opportunity to meet people- $-74 \%$ valued this highly, and only one lone soul felt it to be useless. Rheumatologists rightly feel that there is no substitute for personal contact in discussions, and it is a pleasure to put names to faces.
Mrs Currey (the politician not the rheumatologist) will be pleaseci to learn that $41 \%$ of attenders take their spouses, thus diminishing the temptation of the fleshpots of many free-wheeling conferences. One respondent uttered the plaintive cry, 'She won't come'. The alternative, as I once experienced in a workshop organised by a pharmaceutical company, is to lock up the participants in a remote castle. We were allowed to walk in the grounds between sessions!

It was apparent that the basic scientists were disadvantaged in their ability to attend such conferences-always assuming one does regard it as a disadvantage. The opportunity to listen and talk to colleagues from one's own and different countries was felt to be valuable for single handed consultants without help at senior registrar grade. They have few opportunities to discuss problems, share their own experience, and learn from others. Such isolation may not be appreciated by those working in teaching centres with a smaller workload (presumably the respondent was referring to London). 
Among the enlightened minority of abolitionists, 37 gave reasons for their disquiet. The conferences were felt to be too large by 17 , making them impersonal and giving difficulty in being in the right place at the right time. This disquiet was shared by many who were proponents of international conferences. Had I rephrased the question to 'Do you think large international conferences should be abolished?', I suspect that many more than a quarter would have indicated this desire. The pleasantness and popularity of New Zealand-Australasian conferences is probably explained by the fact that only $100-200$ attend. No serious scientist or clinician should be seen at one, said one respondent, though he did not wish to see them abolished as he was not a serious scientist nor an investigating clinician. Poor quality, outdated material, and little more than 'pot boiling' talks concerned 19. The size of the conferences led to poor organisation and timekeeping at the meetings (six). This led 12 to question the cost effectiveness of such operations, with concern about the dependence on pharmaceutical company money, and guilt feelings about being away from work in three. The razzmatazz was of great concern to seven, their reactions varying from a headache to disgust. One Australian felt that there were too many freeloaders. A number noted that the conferences were tax deductible. A young friend of mine, on being appointed as a lecturer in accountancy, asked me about a research project. I suggested a cost-benefit analysis of international conferences. Within six months he had died-such are the complications of this issue (no foul play was suspected).

Against these reservations have to be set the comments about the value felt by those living in more backward societies (Australia, according to an Australian) and in third world countries. Many find them a useful source of ideas, which promote lateral thinking. Meeting people, either in or close to your area of study, is essential for the free exchange of ideas, problem solving, and initiating collaboration, which cannot be undertaken by letter. A scientist with a pharmaceutical company, who was previously in academia, valued the development of links at such conferences. A registrar found that it rejuvenated his flagging spirits. Others felt we would not understand the different philosophies and methodologies of workers in other countries unless we met them personally.

For myself, I always vow not to attend an international congress, but usually find myself going. As I share the majority view that such value as they have lies in contact with other rheumatologists I make it a policy not to attend any sessions, except those at which I am speaking or chairing. I bring a pile of work and sit comfortably in a readily accessible spot. Then the world may come and speak to me if it wishes, but if it does not then I can work away from telephones. It is a policy in our unit that anyone who attends a conference produces a report which is to be discussed at the next clinical sciences meeting. The number of points worth discussing is a useful criterion of the value of a conference. Fortunately, at international conferences other members of the unit attend, so they can submit the report-it is usualiy short.

International conferences are here to stay, despite their being dubbed 'juggernauts' by Watson Buchanan, whose paper on the subject I cannot trace. Moreover, somewhat to my surprise, the majority favour them. There was little difference between the answers of either sex, of consultants and non-consultants, or of practitioners in different countries. Evelyn Hess believes that they have improved considerably in the last decade and that we need to be involved so that this improvement will be maintained. It is concerning that only $17 \%$ find the conferences of great educational value. Certainly many of the considerations above led the British organising committee of the European Congress of Rheumatology held in Brighton, United Kingdom, to develop a pattern of one or two plenary lectures at the start of the day, followed by smaller workshops on given subjects in which authors had two minutes in which to present salient points of their work before a carefully structured general discussion ensued. The value of that model requires emphasis. Organisers may even wish to consider an educational day before the conferences, one in the middle, and one on the final day. At the same time they would probably need to discourage pharmaceutical companies from organising their own symposia before and after conferences. It would be better if each educational symposium, constructed by the conference's organising committee, was formally sponsored by two or three pharmaceutical companies (whose financial assistance should be clearly acknowledged).

Organisation of such mammoth conferences should be left in the hands of the best professionals, regardless of the cost. Chairmen of sessions need to be carefully chosen and adequately trained. We give insufficient time to teaching deliverers of papers how to communicate their message and to training chairmen how to control a meeting. In the National Health Service we are constantly invited to learn how to manage by managers who seldom take the lessons to heart. In the clinical and scientific community we should be as diligent in teaching staff how to function as well in their public roles as in their scientific research.

Rheumatism and Rehabilitation Research Unit,

V WRIGHT School of Medicine,

36 Clarendon Road,

Leeds IS2 9NZ 